Check for updates

Cite this: RSC Adv., 2017, 7, 40124

\title{
Aligned $\mathrm{Fe}_{3} \mathrm{O}_{4}$ magnetic nanoparticle films by magneto-electrospray method
}

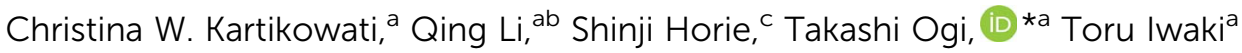 \\ and Kikuo Okuyama ${ }^{a}$
}

This work reports for the first time the preparation and evaluation of aligned $\mathrm{Fe}_{3} \mathrm{O}_{4}$ nanoparticle films via a magneto-electrospray method, i.e., electrospray under a magnetic field. The magnetic field was applied to align the magnetic moment of $\mathrm{Fe}_{3} \mathrm{O}_{4}$ particles. Well-dispersed $\mathrm{Fe}_{3} \mathrm{O}_{4}$ nanoparticles (NPs) with average sizes of 10,25 , and $45 \mathrm{~nm}$ were obtained using a bead-mill dispersion. The $\mathrm{Fe}_{3} \mathrm{O}_{4}$ nanoparticle slurries were mixed with a polyvinyl alcohol (PVA) solution and then deposited on Si-wafers under a $0.1 \mathrm{~T}$ magnetic field. The $\mathrm{Fe}_{3} \mathrm{O}_{4}$ crystalline structures were maintained after both dispersion and deposition, as characterized by $\mathrm{X}$-ray diffraction patterns. Hysteresis curves revealed that the magnetic coercivity $\left(H_{\mathrm{c}}\right)$ of the well-dispersed nanoparticle slurries decreased owing to magnetic interactions among particles. However, the $H_{c}$ values of the films were larger than those of the nanoparticle slurries. The values further increased from the application of a magnetic field during film deposition. This enhancement was attributed to alignment of the magnetic moments of the $\mathrm{Fe}_{3} \mathrm{O}_{4} \mathrm{NPs}$. These results show that tuning of the magnetic properties of materials, such as $\mathrm{Fe}_{3} \mathrm{O}_{4} \mathrm{NPs}$, can be achieved by controlling the alignment of their magnetic moment.

Received 19th July 2017

Accepted 10th August 2017

DOI: $10.1039 / \mathrm{c} 7 \mathrm{ra0} 0794 \mathrm{c}$

rsc.li/rsc-advances magnetic properties of a structured magnetic nanoparticle composite can be controlled by aligning their magnetic moment under a magnetic field, as has been reported in our previous studies on $\alpha^{\prime \prime}-\mathrm{Fe}_{16} \mathrm{~N}_{2}$ NPs. ${ }^{13-16}$ However, well-dispersed NPs are required for this alignment process.

A method for dispersing the NPs in organic solvent is therefore proposed to enable the resulting suspension to mix with polymeric materials related to composite applications. NPs aggregate and agglomerate during the synthesis process, which inhibits their alignment. Our group have succeeded in producing well-dispersed $\mathrm{TiO}_{2}, \mathrm{BN}$, and $\alpha^{\prime \prime}-\mathrm{Fe}_{16} \mathrm{~N}_{2}$ NPs, using a low energy bead-mill dispersion, ${ }^{17-19}$ which had no adverse effects on the NPs shape and structure. Owing to their magnetic interactions, $\mathrm{Fe}_{3} \mathrm{O}_{4}$ NPs agglomerate readily. Therefore, dispersion techniques are required to break-up the agglomerates and obtain well-dispersed magnetic NPs prior to their structuration in a magnetic nanoparticle composite.

The formation of $\mathrm{Fe}_{3} \mathrm{O}_{4}$ nanoparticle composites in the form of a film is preferable for demonstrating the magnetic alignment process. Several methods have been widely reported for preparing $\mathrm{Fe}_{3} \mathrm{O}_{4}$ films including molecular beam epitaxy, ${ }^{20,21}$ sputtering, ${ }^{22}$ electrodeposition, ${ }^{23}$ and pulsed laser deposition. $^{\mathbf{2 4 , 2 5}}$ However, these film preparation methods are not capable of preparing composite films with controlled compositions, structures, and magnetic properties. Thus, it is important to develop preparation methods, which enable control over the $\mathrm{Fe}_{3} \mathrm{O}_{4}$ composition, structure, and magnetic properties. Electrospray techniques are considered as a promising method
${ }^{a}$ Department of Chemical Engineering, Graduate School of Engineering, Hiroshima University, 1-4-1 Kagamiyama, Higashi-Hiroshima 739-8527, Japan. E-mail: ogit@ hiroshima-u.ac.jp

${ }^{b}$ Department of Environmental Science and Engineering, Fudan University, Shanghai 200-433, China

${ }^{c}$ Technical Strategy Department, Research and Development Division Toda Kogyo Corporation, Otake, Hiroshima 739-0652, Japan 
for film deposition from various precursor solutions. Droplets produced by electrospray are highly charged and have a high deposition efficiency. ${ }^{26-29}$ Electrospray method has also been recently reported to be effective for fabrication of a carbon nanotube forest-like film from a carbon nanotube suspension. ${ }^{30}$

With the aim of producing structured magnetic $\mathrm{Fe}_{3} \mathrm{O}_{4} \mathrm{NPs}$ with controllable magnetic properties, this study reports dispersion of $\mathrm{Fe}_{3} \mathrm{O}_{4}$ NPs followed by deposition via a magnetoelectrospray method. The studied samples included superparamagnetic and single domain $\mathrm{Fe}_{3} \mathrm{O}_{4} \mathrm{NPs}$ that were produced under well-controlled crystal growth conditions on a large scale. An external magnetic field of $0.1 \mathrm{~T}$ was applied during deposition to align the magnetic moment of the $\mathrm{Fe}_{3} \mathrm{O}_{4}$ NPs in the films. The effects of the dispersion process on the particle morphology and magnetic properties were evaluated together with the effects of the magnetic field on the morphology and magnetic properties of the deposited films.

\section{Experimental}

\subsection{Materials}

The $\mathrm{Fe}_{3} \mathrm{O}_{4}$ NPs used in this study had mean size of 10,25 , and $45 \mathrm{~nm}$ and were prepared by a large-scale liquid precipitation method with precise control of the $\mathrm{Fe}^{2+}$ concentration, $\mathrm{pH}$, temperature, and aeration rate as described in a patent no. US 5843610 A (Toda Kogyo Co. Ltd, Japan). ${ }^{31}$ PVA was purchased from Kanto Chemicals, Tokyo, Japan, and was used directly without further treatment or purification.

\subsection{Dispersion of the $\mathrm{Fe}_{3} \mathrm{O}_{4} \mathrm{NPs}$}

The initial slurry for dispersion was prepared by mixing $5 \mathrm{~g}$ of $\mathrm{Fe}_{3} \mathrm{O}_{4}$ NPs with $308.75 \mathrm{~g}$ of water and adding $3 \mathrm{~mL} \mathrm{NH}_{4} \mathrm{OH}$ to adjust the $\mathrm{pH}$ to $\sim 9$. This slurry was stirred for $30 \mathrm{~min}$ prior to dispersion and added to the mixing tank of a bead-mill dispersion apparatus with $30 \mu \mathrm{m} \mathrm{ZrO}_{2}$ beads (dual axial type bead-mill, Kotobuki Industries, Co. Ltd., Japan). The dispersion process was conducted for $60 \mathrm{~min}$ with a rotation speed of $6 \mathrm{~m}$ $\mathrm{s}^{-1}$. This dispersion process was conducted in the same manner as that described in previous reports. ${ }^{17,18}$

\subsection{Preparation of $\mathrm{Fe}_{3} \mathrm{O}_{4}$ nanoparticle films by magneto- electrospray}

The precursor solution was made from a mixture of aqueous PVA (1.0 wt\%) solution and $\mathrm{Fe}_{3} \mathrm{O}_{4}$ NPs (1.5 wt\%) suspended in ultra-pure water. The mass mixing ratio was $1: 1$, giving a mass ratio of the PVA and $\mathrm{Fe}_{3} \mathrm{O}_{4}$ NPs of $2: 3$. The solution was loaded into a syringe pump (PhD 2000, Harvard Apparatus, USA), which was used to control the solution flow rate and set to a fixed rate of $20.0 \mu \mathrm{L} \mathrm{min}{ }^{-1}$. The internal and external diameters of the needle used were 0.48 and $0.70 \mathrm{~mm}$, respectively. An aluminum plate was placed facing the needle tip at a distance of $12 \mathrm{~cm}$. Silicon wafers were attached to the plate and used as substrates to collect the samples sprayed out from the needle tip. Voltages of +6.0 and $-6.0 \mathrm{kV}$ were applied to the needle tip and the aluminum plate, respectively. An external magnetic field of $0.1 \mathrm{~T}$ was applied to the substrate, perpendicular to the collector, by a permanent magnet, in a similar arrangement to that described in our previous paper. ${ }^{\mathbf{1 4}}$ For analysing the properties of the deposited film, samples are taken from the center part of the permanent magnet to minimize the magnetic field gradient. The experiment was conducted under controlled conditions of $30 \pm 2{ }^{\circ} \mathrm{C}$ and a relative humidity of $35 \pm 4 \%$. The preparation route to the $\mathrm{Fe}_{3} \mathrm{O}_{4}$ nanoparticle films is illustrated in Fig. 1 .

\subsection{Characterization}

The morphologies of the $\mathrm{Fe}_{3} \mathrm{O}_{4}$ NPs and films were observed with a field emission scanning electron microscope (FE SEM; Hitachi S-5000, Japan) and a transmission electron microscope (TEM; JEM-3000F, JEOL, Japan). The crystalline structure of the NPs was examined by X-ray diffraction (XRD; D2 Phaser, Bruker, Germany). Their magnetic properties were evaluated on a superconducting quantum interference device (SQUID, Quantum Design, USA). Magnetization was measured as a function of applied field from 1 to $50 \mathrm{kOe}$ at $300 \mathrm{~K}$.

\section{Results and discussion}

\subsection{Dispersion of the $\mathrm{Fe}_{3} \mathrm{O}_{4}$ NPs}

Fig. 2 shows the morphology of the $\mathrm{Fe}_{3} \mathrm{O}_{4}$ NPs before and after dispersion. The mean sizes of these NPs were 10, 25, and $45 \mathrm{~nm}$ in the Fig. 2(a, d), (b, e) and (c, f), respectively. The SEM images (Fig. 2(a-c)) show that the $\mathrm{Fe}_{3} \mathrm{O}_{4}$ NPs were agglomerated before dispersion. Owing to the agglomeration of the as-prepared $\mathrm{Fe}_{3} \mathrm{O}_{4} \mathrm{NPs}$, the dispersion step was required to break up agglomerates prior to nanoparticle film preparation. The morphology of the $\mathrm{Fe}_{3} \mathrm{O}_{4}$ NPs after dispersion is shown in Fig. 2(d-f). These TEM images show that after dispersion, nonagglomerated particles without any necking among the particles were obtained. The images also indicated that the morphology of NPs was unaffected by the dispersion process. The XRD patterns in Fig. 3 confirm that the crystal structure of the $\mathrm{Fe}_{3} \mathrm{O}_{4}$ NPs after the bead-mill dispersion did not change compared to that before bead-mill dispersion. The XRD patterns of the 10 and $45 \mathrm{~nm}$ NPs show the same result. Thus, the bead-mill dispersion process produced well-dispersed $\mathrm{Fe}_{3} \mathrm{O}_{4}$

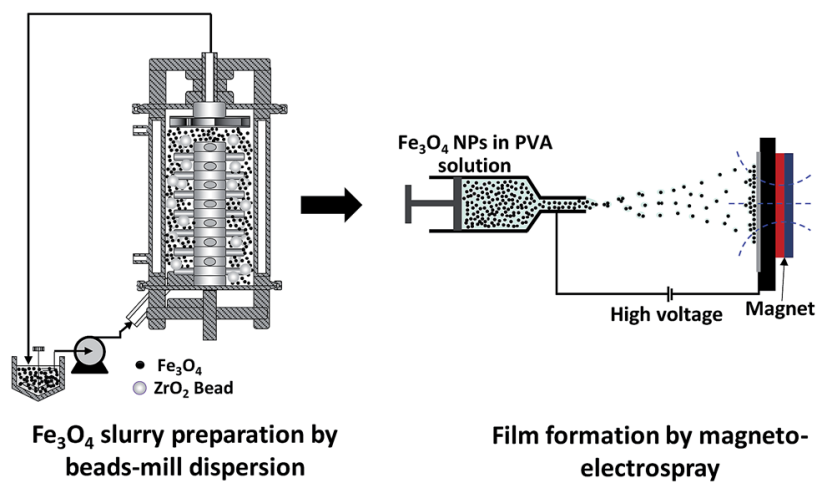

Fig. 1 Schematic illustration of the preparation process of $\mathrm{Fe}_{3} \mathrm{O}_{4}$ nanoparticle films. 

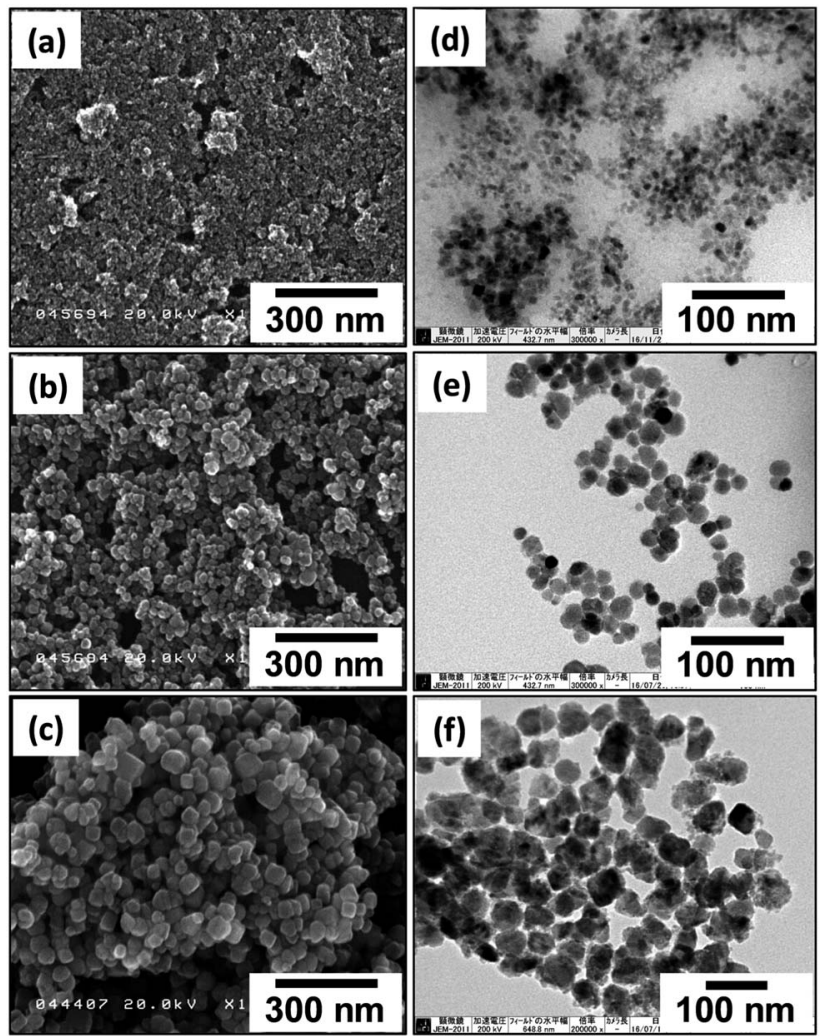

Fig. 2 SEM and TEM images of $\mathrm{Fe}_{3} \mathrm{O}_{4}$ nanoparticles before $(\mathrm{a}-\mathrm{c})$ and after $(d-f)$ bead-mill dispersion. Mean sizes of the nanoparticles were 10 ( $a$ and $d), 25$ (b and e), and $45 \mathrm{~nm}$ (c and f).

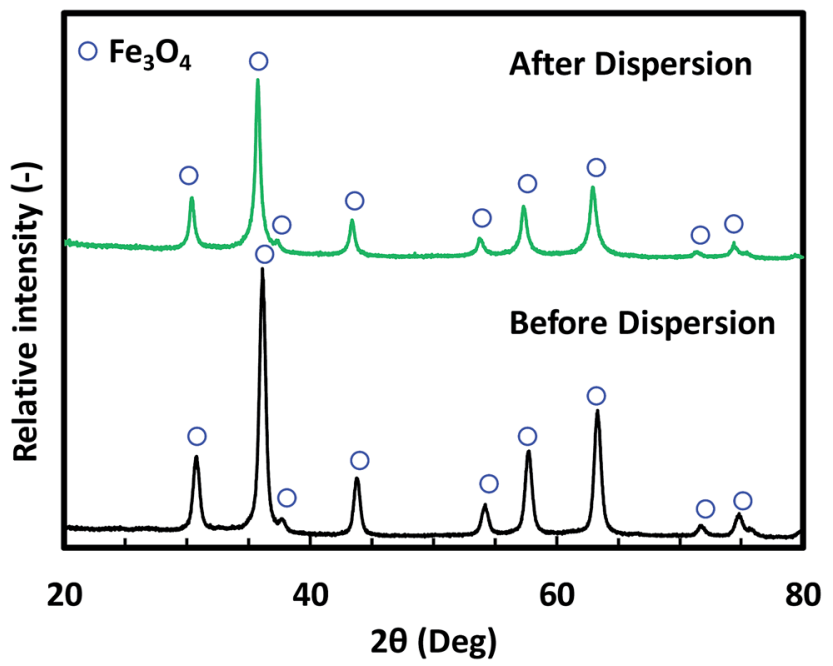

Fig. 3 XRD patterns of $25 \mathrm{~nm} \mathrm{Fe}_{3} \mathrm{O}_{4}$ nanoparticles before and after dispersion.

NPs without affecting the structure of the particles, consistent with our previous studies. ${ }^{17-19}$

Fig. 4 shows the hysteresis loops of the 10, 25, and $45 \mathrm{~nm}$ $\mathrm{Fe}_{3} \mathrm{O}_{4}$ NPs before and after dispersion. The saturation magnetization $\left(M_{\mathrm{S}}\right)$ of the $\mathrm{Fe}_{3} \mathrm{O}_{4}$ NPs was similar before $(\sim 67.6 \mathrm{emu}$ $\left.\mathrm{g}^{-1}\right)$ and after dispersion $\left(\sim 67.1\right.$ emu $\left.\mathrm{g}^{-1}\right)$. Conversely, the $H_{\mathrm{c}}$
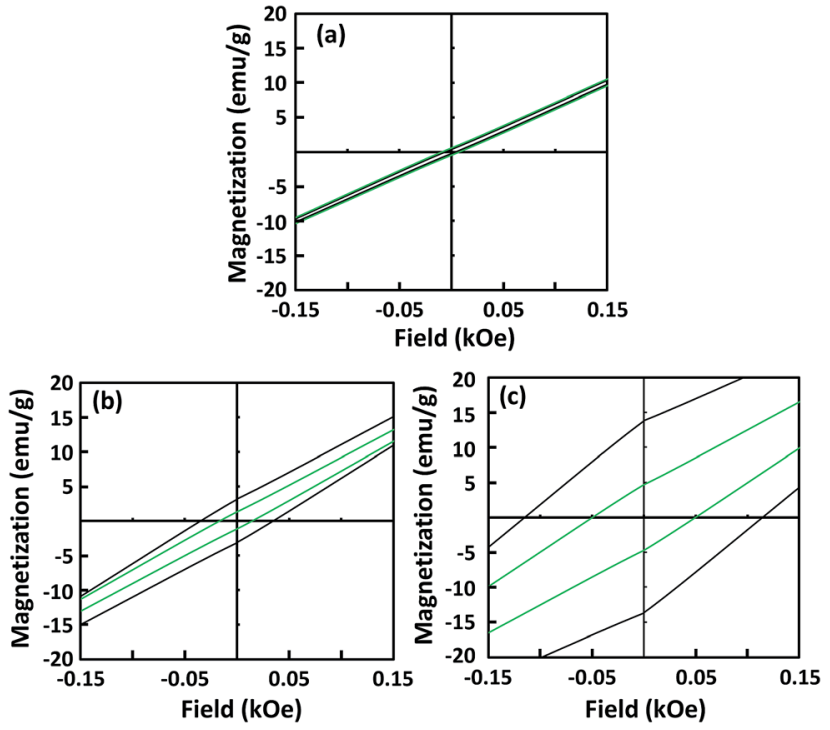

Fig. 4 Hysteresis loops of 10 (a), 25 (b), and 45 nm (c) $\mathrm{Fe}_{3} \mathrm{O}_{4}$ nanoparticles. Black and green lines correspond to before and after dispersion, respectively.

values of the dispersed single-domain $\mathrm{Fe}_{3} \mathrm{O}_{4}$ NPs were slightly lower than those before dispersion. The $H_{\mathrm{c}}$ values of the 25 and $45 \mathrm{~nm} \mathrm{Fe}_{3} \mathrm{O}_{4}$ NPs before dispersion were 37.5, and $126.8 \mathrm{Oe}$, respectively. After dispersion, the $H_{\mathrm{c}}$ values decreased to 17.5 and 53.1 Oe, respectively. This decrease in $H_{c}$ was caused by magnetic dipole coupling among the dispersed NPs. This result is consistent with previous reports on the dispersion of singledomain $\alpha^{\prime \prime}-\mathrm{Fe}_{16} \mathrm{~N}_{2}$ NPs. ${ }^{19}$ The similarity suggests that the decrease of $H_{\mathrm{c}}$ after dispersion is a typical characteristic of single-domain magnetic NPs. During the SQUID measurement, when the magnetic field was removed, the well-dispersed NPs were able to move easily, allowing coupling of their magnetic moments. This coupling provided a demagnetization field, which led to a decrease in the $H_{\mathrm{c}}$ value. For the superparamagnetic NPs, the $H_{\mathrm{c}}$ value was close to zero and the dispersion process did not affect the $H_{\mathrm{c}}$.

\section{2 $\mathrm{Fe}_{3} \mathrm{O}_{4}$ nanoparticle deposited films}

The well-dispersed $\mathrm{Fe}_{3} \mathrm{O}_{4}$ NPs were deposited on a Si-wafer by an electrospray method. Fig. 5 shows the surface morphologies of the deposited films prepared from the three sizes of $\mathrm{Fe}_{3} \mathrm{O}_{4}$ NPs, i.e., $10 \mathrm{~nm}(\mathrm{a}, \mathrm{b}) ; 25 \mathrm{~nm}$ (c, d); and $45 \mathrm{~nm}$ (e, f), from depositions without (a, c, e) and with (b, d, f) a magnetic field. Cross-sectional SEM images $(\mathrm{g}, \mathrm{h})$ show the films deposited from the $25 \mathrm{~nm} \mathrm{Fe}_{3} \mathrm{O}_{4}$ NPs. The surface of the single-domain NPs (25 and $45 \mathrm{~nm}$ ) showed a different morphology from that of the superparamagnetic NPs $(10 \mathrm{~nm})$. The films prepared under magnetic fields also showed a different surface morphology from the films deposited without a magnetic field. When the magnetic field was applied during the deposition, the film surface formed spike-like shapes. This pattern is generally observed in ferrofluids under a magnetic field. ${ }^{32}$ This phenomenon is consistent with a previous report of $\alpha^{\prime \prime}-\mathrm{Fe}_{16} \mathrm{~N}_{2}$ 
NPs films prepared by spin-coating. ${ }^{13,15}$ The cross-sectional SEM images of films deposited under a magnetic field showed that the $\mathrm{Fe}_{3} \mathrm{O}_{4}$ NPs were dispersed inside the film.

For the case of the nanoparticle film deposited from superparamagnetic NPs, the SEM images showed a forest-like morphology both in the presence and absence of an applied magnetic field. This different morphology might be attributed to the small particle size and their magnetic properties. The residual magnetism, i.e., the magnetic $\left(M_{\mathrm{r}}\right)$ remanence, value was zero for the superparamagnetic NPs and increased as the particle size of the single-domain NPs increased. ${ }^{33}$ Residual magnetic forces can increase aggregation of particles during the water evaporation process, which can in turn prevent droplet dispersion by electrostatic forces of the electrospray system. Additionally, the $\mathrm{Fe}_{3} \mathrm{O}_{4}$ nanoparticle size also limits the
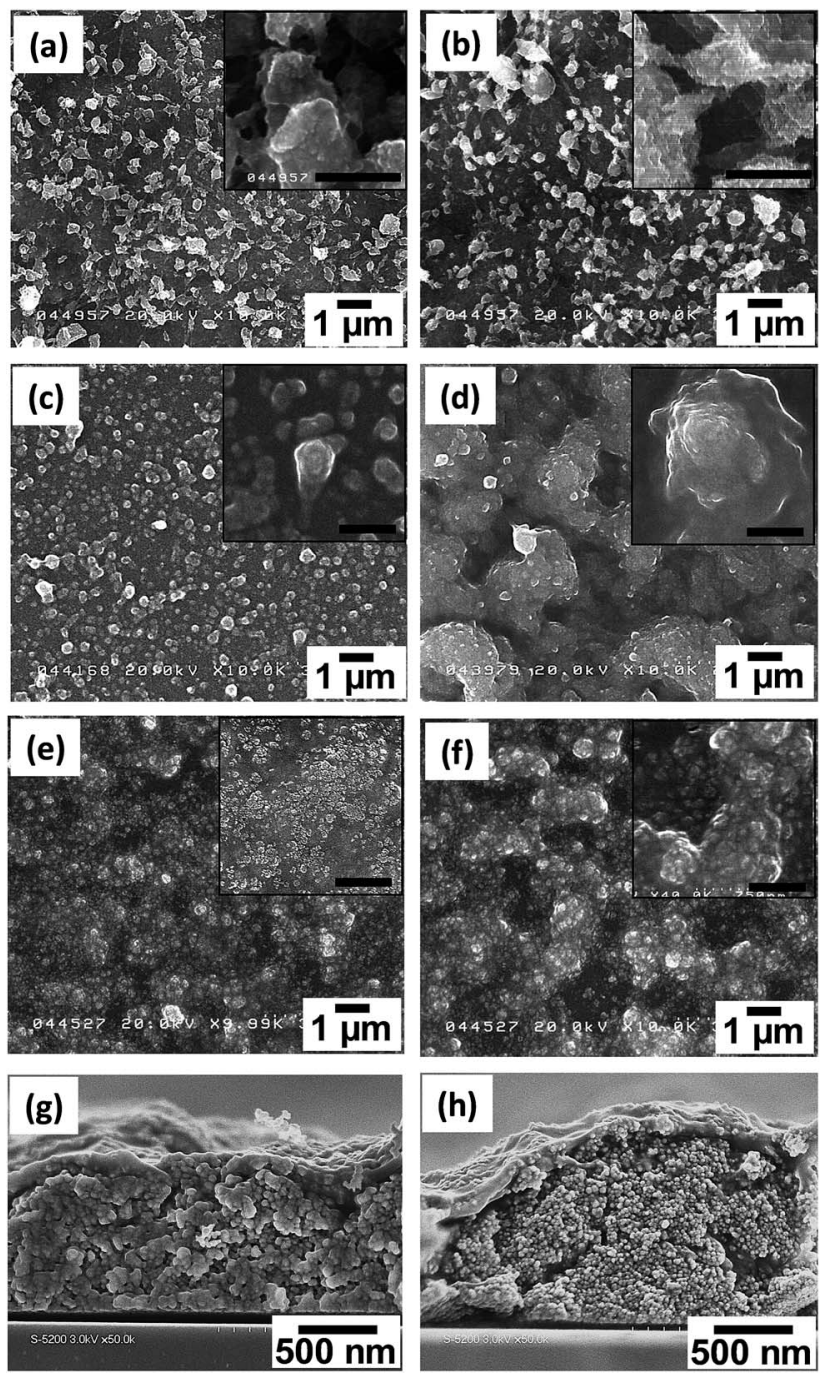

Fig. 5 SEM images of magnetic films constituting $\mathrm{Fe}_{3} \mathrm{O}_{4} \mathrm{NPs}$ with sizes of (a, b) $10 \mathrm{~nm}$, (c, d) $25 \mathrm{~nm}$, and (e, f) $45 \mathrm{~nm}$. The films shown in (a), (c), and (e) were deposited without a magnetic field, while those in (b, d, and f) were deposited with a magnetic field. The inset figures show high magnification SEM images with a scale bar of $100 \mathrm{~nm}$. (g) and (h) are cross sectional SEM images of $25 \mathrm{~nm}$ nanoparticle films deposited without and with a magnetic field, respectively. minimum size of the final droplet formed between leaving the needle tip and deposition on the substrate. The small $\mathrm{Fe}_{3} \mathrm{O}_{4} \mathrm{NPs}$ enabled formation of small droplets, which deposited as films with a fine structure. According to previous analysis, ${ }^{30}$ higher conductivity of the droplet and substrate surface will also promote the formation of a forest-like structure.

XRD patterns of selected nanoparticle films composed of $25 \mathrm{~nm} \mathrm{Fe}_{3} \mathrm{O}_{4}$ NPs featured typical $\mathrm{Fe}_{3} \mathrm{O}_{4}$ crystalline structures, as shown in Fig. 6. The $10 \mathrm{~nm}$ and $45 \mathrm{~nm} \mathrm{Fe}_{3} \mathrm{O}_{4}$ films show similar XRD patterns. The XRD peaks of (111), (311), (222), and (400) from crystalline $\mathrm{Fe}_{3} \mathrm{O}_{4}$ were visible in the $2 \theta$ range of $25-$ $60^{\circ}$. This pattern agreed with typical results of magnetite crystals. ${ }^{34}$ Thus, the prepared films retained the inherent crystalline properties of the NPs. The differences in the baseline of the XRD patterns likely originates from the PVA component in the film. Unlike a $\alpha^{\prime \prime}-\mathrm{Fe}_{16} \mathrm{~N}_{2}$ nanoparticle film, ${ }^{15}$ alignment of the easy axis of the particles did not affect the intensity of their XRD spectrum. This result can be attributed to the weak magnetic field applied, and the relatively weak magnetic properties of the $\mathrm{Fe}_{3} \mathrm{O}_{4}$ NPs compared with those of $\alpha^{\prime \prime}-\mathrm{Fe}_{16} \mathrm{~N}_{2}$ NPs.

Fig. 7 shows hysteresis loops of films composed of three sizes of $\mathrm{Fe}_{3} \mathrm{O}_{4}$ NPs, deposited with and without the influence of the magnetic field. Compared with the $H_{\mathrm{c}}$ values of the precursor NPs, those of the deposited films increased and decreased when measured parallel and perpendicular to the film surfaces, respectively, as shown in Fig. 7(a), (c) and (e). This anisotropy resulted from stronger interactions among the magnetic NPs along the film surface direction than the interactions in the perpendicular direction. The difference of the $H_{\mathrm{c}}$ values was more pronounced when the magnetic field was applied, as shown in Fig. 7(b), (d) and (f). Additionally, the magnetic field generated by the permanent magnet was not uniformly distributed over the substrate surface and the field gradient along the surface direction was higher than that perpendicular to the surface. Owing to the magnetic NPs preference for moving along the field gradient, the number density distribution of the $\mathrm{Fe}_{3} \mathrm{O}_{4}$ NPs along the film surface could be enhanced

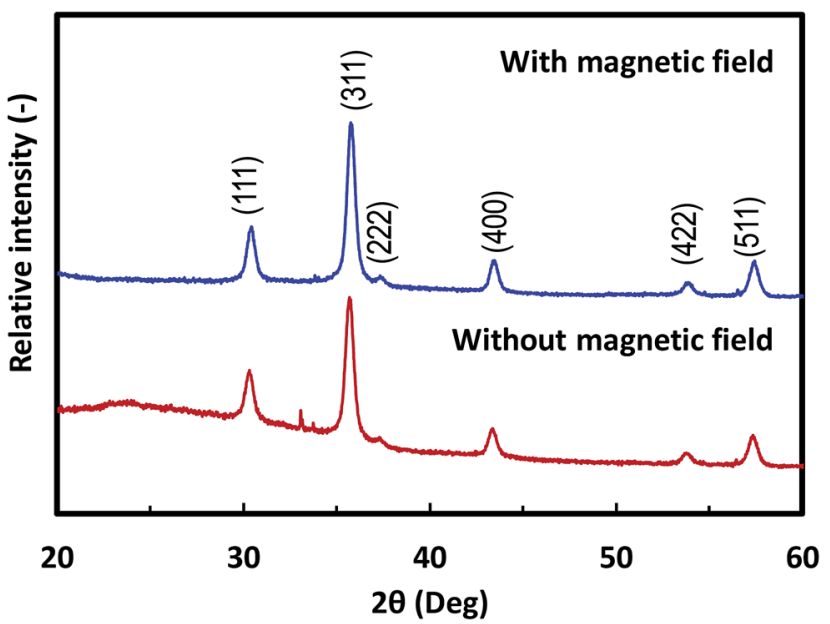

Fig. 6 XRD patterns of magnetic films composed of $25 \mathrm{~nm} \mathrm{Fe} \mathrm{O}_{4}$ nanoparticles deposited with and without a magnetic field. 

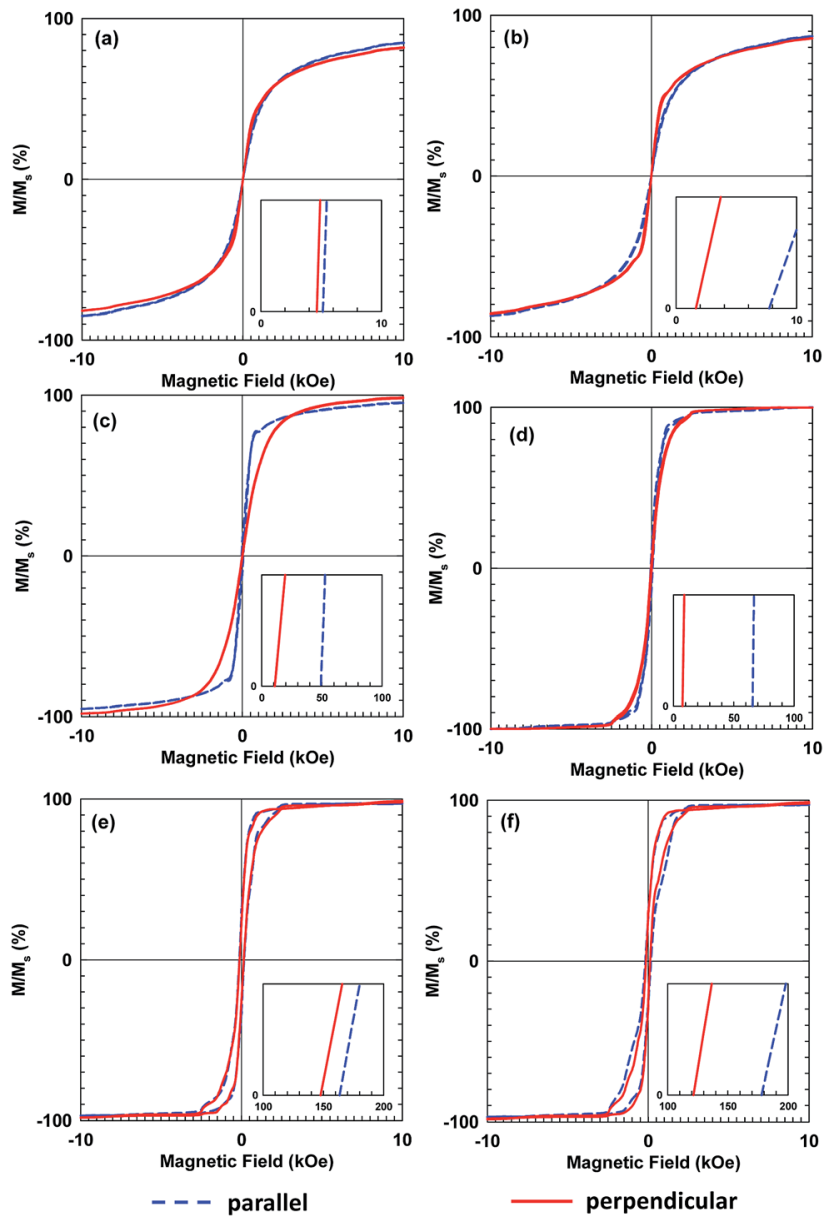

Fig. 7 Hysteresis loops of magnetic films composed of $\mathrm{Fe}_{3} \mathrm{O}_{4}$ nanoparticles with sizes of (a, b) $10 \mathrm{~nm}$, (c, d) $25 \mathrm{~nm}$, and (e, f) $45 \mathrm{~nm}$. Films of (a), (c), and (e) were deposited without a magnetic field, while those of (b), (d), and (f) were deposited with a magnetic field.

by applying a non-uniform magnetic field..$^{35}$ This result emphasizes the alignment of the magnetic moments of the NPs. The application of the magnetic field during the film deposition aligned the magnetic moments of the NPs, which increased the $H_{\mathrm{c}}$ and $M_{\mathrm{r}}$ values of the film. This result was consistent with those for $\alpha^{\prime \prime}-\mathrm{Fe}_{16} \mathrm{~N}_{2}$ NPs. ${ }^{13-15}$

The smaller $H_{\mathrm{c}}$ value, which was measured perpendicular to the film surface emphasizes the alignment of the magnetic moment of the $\mathrm{Fe}_{3} \mathrm{O}_{4}$ NPs. Their magnetic moments aligned perpendicular to the film surface in the direction of the magnetic field. The $H_{\mathrm{c}}$ value of the films deposited from $10 \mathrm{~nm}$ $\mathrm{Fe}_{3} \mathrm{O}_{4}$ NPs was close to zero and did not increase as much as those of the single-domain NPs with larger diameters. The single-domain NPs showed a noticeable enhancement of their magnetic properties owing to the alignment of their magnetic moments. The relationship between the enhancement of the $H_{\mathrm{c}}$ value and the particle size, is illustrated in Fig. 8. This figure shows that the enhancement of the $H_{\mathrm{c}}$ value increased as the particle diameter increased. The $H_{\mathrm{c}}$ value of magnetic NPs is known to increase to a certain maximum value before decreasing to zero with decreasing particle size. Structuring of

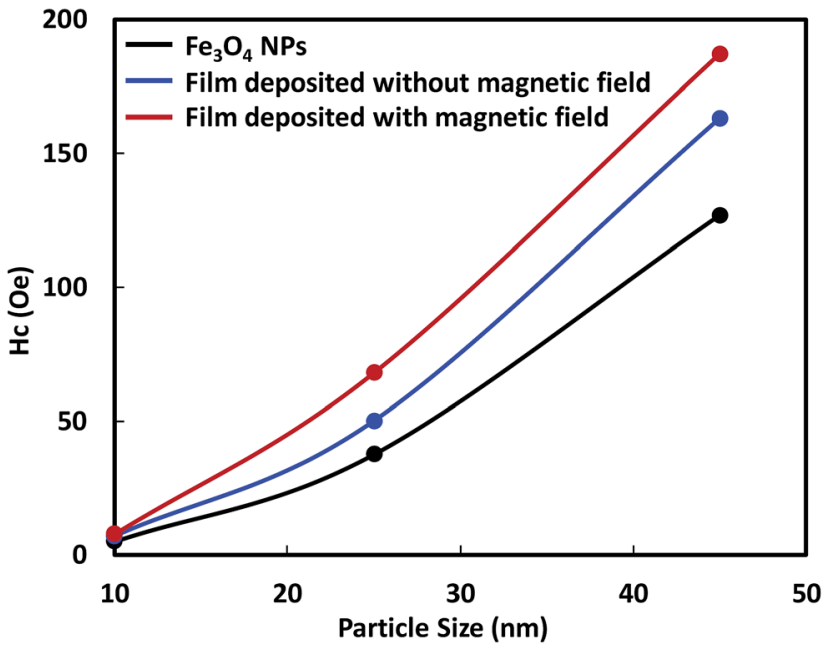

Fig. 8 Correlation of the coercivity of the $\mathrm{Fe}_{3} \mathrm{O}_{4}$ nanoparticle film with constituent particle size.
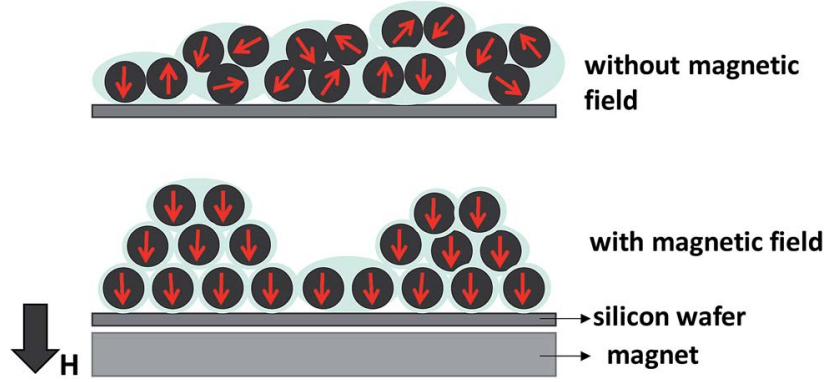

Fig. 9 Illustration of the magnetic nanoparticle direction inside films deposited with and without a magnetic field.

the particles to achieve the highest $H_{\mathrm{c}}$ value under the magnetic field is preferable for their application in magnetic films or bulk magnets. Single-domain NPs, which have a single magnetic moment show better structuring than multi-domain NPs. In addition, single domain NPs have stronger magnetic properties than multi-domain NPs.

Fig. 9 illustrates the phenomenon of the magnetic moment direction inside the film which is located on the center part of the permanent magnet. During the electrospray, the magnetic field produced a driving force that led to the formation of a smaller cone jet. ${ }^{14}$ The smaller cone jet further produced smaller droplets, which contained fewer $\mathrm{Fe}_{3} \mathrm{O}_{4}$ NPs. Under the applied magnetic field, the electric current can be used to control the cone-jet geometry to reduce the spinning jet instability. ${ }^{27}$ Therefore, the needle tip generated a uniform cone-jet resulting in uniform droplets. The magnetic moments of the $\mathrm{Fe}_{3} \mathrm{O}_{4}$ NPs inside the film aligned along the direction of the magnetic field.

\section{Conclusion}

The preparation and evaluation of uniform aligned $\mathrm{Fe}_{3} \mathrm{O}_{4}$ nanoparticle films via magneto-electrospray is reported for the 
first time. A well-dispersed $\mathrm{Fe}_{3} \mathrm{O}_{4}$ NPs in water slurry was prepared by bead-mill dispersion. The $\mathrm{Fe}_{3} \mathrm{O}_{4}$ NPs slurry was then mixed with a PVA solution to prepare the film via electrospray under the influence of a $0.1 \mathrm{~T}$ magnetic field. The dispersion process successfully broke-up agglomerated $\mathrm{Fe}_{3} \mathrm{O}_{4}$ NPs into their primary sizes without affecting their shape or structure. XRD results confirmed that the deposition process did not change the crystalline structure of the $\mathrm{Fe}_{3} \mathrm{O}_{4}$ NPs. Although the $H_{\mathrm{c}}$ values of the $\mathrm{Fe}_{3} \mathrm{O}_{4}$ nanoparticle slurries decreased, the values were enhanced in their films after deposition. We obtained further enhancement of the $H_{\mathrm{c}}$ values via the application of a magnetic field during the film deposition. This enhancement of the $H_{\mathrm{c}}$ value increased as the diameter of the constituent NPs increased. These results indicate that electrospray deposition methods with an applied magnetic field has good potential for structuring magnetic NPs with controllable magnetic properties.

\section{Conflicts of interest}

There are no conflicts to declare.

\section{Acknowledgements}

We gratefully acknowledge the Ministry of Education, Culture, Sports, Science, and Technology (MEXT) of Japan for providing Scholarships (C. $\cdot$ W. $\cdot$ K.). This work was also supported by JSPS KAKENHI Grant Number 26709061 and 16K13642. This work is partly supported by the Center for Functional Nano Oxide at Hiroshima University. The authors thank Professor Toshiro Takabatake and Associate Professor Takahiro Onimaru from the Department of Quantum Matter, Graduate School of Advanced Sciences of Matter, Hiroshima University, for SQUID measurements and Dr Makoto Maeda from the Natural Science Center for Basic Research and Development (NBARD), Hiroshima University, for TEM analysis.

\section{Notes and references}

1 F. Wortmann and K. Flüchter, Business \& Information Systems Engineering, 2015, 57, 221-224.

2 T. A. P. Rocha-Santos, TrAC, Trends Anal. Chem., 2014, 62, 2836.

3 N. Liakakos, T. Blon, C. Achkar, V. Vilar, B. Cormary, R. P. Tan, O. Benamara, G. Chaboussant, F. Ott, B. WarotFonrose, E. Snoeck, B. Chaudret, K. Soulantica and M. Respaud, Nano Lett., 2014, 14, 3481-3486.

4 C. Chappert, A. Fert and F. N. Van Dau, Nat. Mater., 2007, 6, 813-823.

5 Y. V. Kolen'ko, M. Bañobre-López, C. Rodríguez-Abreu, E. Carbó-Argibay, A. Sailsman, Y. Piñeiro-Redondo, M. F. Cerqueira, D. Y. Petrovykh, K. Kovnir, O. I. Lebedev and J. Rivas, J. Phys. Chem. C, 2014, 118, 8691-8701.

6 K. Yoo, B. G. Jeon, S. H. Chun, D. R. Patil, Y. J. Lim, S. H. Noh, J. Gil, J. Cheon and K. H. Kim, Nano Lett., 2016, 16, 74087413.

7 E. D. Daniel and I. Levine, J. Acoust. Soc. Am., 1960, 32, 1.
8 J. P. Hong, S. B. Lee, Y. W. Jung, J. H. Lee, K. S. Yoon, K. W. Kim, C. O. Kim, C. H. Lee and M. H. Jung, Appl. Phys. Lett., 2003, 83, 1590-1592.

9 T. Yamada, K. Morita, K. Kume, H. Yoshikawa and K. Awaga, J. Mater. Chem. C, 2014, 2, 5183.

10 D. Ling and T. Hyeon, Small, 2013, 9, 1450-1466.

11 M. S. Lin and H. J. Leu, Electroanalysis, 2005, 17, 2068-2073.

12 C. T. Yavuz, J. T. Mayo, W. W. Yu, A. Prakash, J. C. Falkner, S. Yean, L. Cong, H. J. Shipley, A. Kan, M. Tomson, D. Natelson and V. L. Colvin, Science, 2006, 314, 964-967.

13 A. Suhendi, C. W. Kartikowati, R. Zulhijah, T. Ogi, T. Iwaki and K. Okuyama, Adv. Powder Technol., 2015, 26, 1618-1623.

14 C. W. Kartikowati, A. Suhendi, R. Zulhijah, T. Ogi, T. Iwaki and K. Okuyama, Nanotechnology, 2016, 27, 025601.

15 C. W. Kartikowati, A. Suhendi, R. Zulhijah, T. Ogi, T. Iwaki and K. Okuyama, Nanoscale, 2016, 8, 2648-2655.

16 T. Ogi, A. B. D. Nandiyanto and K. Okuyama, Adv. Powder Technol., 2014, 25, 3-17.

17 T. Ogi, R. Zulhijah, T. Iwaki and K. Okuyama, KONA Powder Part. J., 2017, 34, 3-23.

18 T. Tahara, Y. Imajyo, A. B. D. Nandiyanto, T. Ogi, T. Iwaki and K. Okuyama, Adv. Powder Technol., 2014, 25, 14921499.

19 R. Zulhijah, A. Suhendi, K. Yoshimi, C. W. Kartikowati, T. Ogi, T. Iwaki and K. Okuyama, Langmuir, 2015, 31, 6011-6019.

20 S. Gálvez, J. Rubio-Zuazo, E. Salas-Colera, A. Muñoz-Noval and G. R. Castro, Appl. Phys. Lett., 2014, 105, 241603.

21 X. Guan, G. Zhou, W. Xue, Z. Quan and X. Xu, APL Mater., 2016, 4, 036104.

22 P. Prieto, J. de la Figuera, L. Martín-García, J. E. Prieto and J. F. Marco, J. Mater. Chem. C, 2016, 4, 7632-7639.

23 C. Zhao, Y. Ma, C. Shen and W. Han, J. Nanosci. Nanotechnol., 2016, 16, 950-955.

24 M. Monti, M. Sanz, M. Oujja, E. Rebollar, M. Castillejo, F. J. Pedrosa, A. Bollero, J. Camarero, J. L. F. Cuñado, N. M. Nemes, F. J. Mompean, M. Garcia-Hernández, S. Nie, K. F. McCarty, A. T. N'Diaye, G. Chen, A. K. Schmid, J. F. Marco and J. de la Figuera, J. Appl. Phys., 2013, 114, 223902.

25 R. Takahashi, H. Misumi and M. Lippmaa, Cryst. Growth Des., 2012, 12, 2679-2683.

26 H. M. Lee, S. G. Kim, I. Matsui, T. Iwaki, F. Iskandar, I. W. Lenggoro and K. Okuyama, J. Magn. Magn. Mater., 2007, 313, 62-68.

27 A. Suhendi, M. M. Munir, A. B. Suryamas, A. B. D. Nandiyanto, T. Ogi and K. Okuyama, Adv. Powder Technol., 2013, 24, 532-536.

28 A. Suhendi, A. B. Nandiyanto, M. M. Munir, T. Ogi, L. Gradon and K. Okuyama, Langmuir, 2013, 29, 13152-13161.

29 A. Suhendi, A. B. D. Nandiyanto, M. M. Munir, T. Ogi and K. Okuyama, Mater. Lett., 2013, 106, 432-435.

30 Q. Li, C. W. Kartikowati, T. Ogi, T. Iwaki and K. Okuyama, Carbon, 2017, 115, 116-119. 
31 N. Uchida, K. Fujioka, K. Aoki, H. Misawa and M. Kozawa, Magnetic particles for magentic toner and process for producing the same, Toda Kogyo Corporation, US Pat., 5843610, 1998.

32 N. A. Clark, Nature, 2013, 504, 229-230.
33 D. Kim, N. Lee, M. Park, B. H. Kim, K. An and T. Hyeon, J. Am. Chem. Soc., 2009, 131, 454-455.

34 S. Sun and H. Zeng, J. Am. Chem. Soc., 2002, 124, 8204-8205. 35 G. Sreenivasulu, M. Popov, R. Zhang, K. Sharma, C. Janes, A. Mukundan and G. Srinivasan, Appl. Phys. Lett., 2014, 104, 052910. 